\title{
Aplicação ao solo de cinza de casca de arroz como fonte de silício: efeito na qualidade de sementes de trigo produzidas sob stresse salino
}

\section{Application to soil of rice husk ash as silicon source: effect in wheat seeds quality produced under salt stress}

\author{
César I. S. Castellanos*, Mariana P. da Rosa, Cristiane Deuner, Alberto Bohn, Antonio C. S. A. \\ Barros e Géri E. Meneghello
}

\begin{abstract}
Departamento de Fitotecnia, Faculdade de Agronomia Eliseu Maciel, Universidade Federal de Pelotas, Campus Universitário S/N, Caixa Postal 354: 96010900. Capão do Leão - RS, Brasil. ( ${ }^{\star}$ E-mail: cesarivansuarez@gmail.com)
\end{abstract}

http://dx.doi.org/10.19084/RCA15011

Recebido/received: 2015.02 .10

Aceite/accepted: 2015.05.31

\section{RES U MO}

O trigo representa 30\% da produção mundial de cereais e no Brasil ocupou a quinta maior área semeada na safra 2012/2013. A produtividade agrícola no mundo pode ser limitada pelos efeitos da salinidade em torno de 50\% das áreas regadas usadas na agricultura. O silício pode conferir tolerância das plantas ao sal convertendo-se em alternativa de gestão contra esse stresse. $\mathrm{O}$ ensaio foi realizado em baldes numa estufa-de-vegetação sob um esquema fatorial $3 \times 4$ com quatro repetições em delineamento inteiramente casualizado, sendo o stresse salino o primeiro fator, causado pela rega realizada durante toda a cultura com cloreto de sódio $(\mathrm{NaCl})$, em doses de 0 (controlo); 8 e 16 mM e o segundo fator, a fertilização com doses de $\mathrm{SiO}_{2}$ de 0 (controlo); 1000; 2000 e $3000 \mathrm{~kg} \mathrm{ha}^{-1}$, usando como fonte a cinza de casca de arroz. Doses até $2000 \mathrm{~kg} \mathrm{ha}^{-1}$, conduziram a um aumento do número de espigas e do peso de sementes por planta. A aplicação de cinza de casca de arroz aumentou o peso de mil sementes e não afetou a germinação das sementes produzidas nem a massa da matéria seca das plântulas oriundas das ditas sementes.

Palavras-chave: casca de arroz, qualidade fisiológica, silício, Triticum aestivum L.

\section{A B S T R A C T}

Wheat grain represents about 30\% of world cereal production and in Brazil it occupied the fifth largest area sown in 2012/2013. Crops productivity can be limited by the effect of salinity in about $50 \%$ of the irrigated land used in the agriculture. Silicon may confer plant tolerance to salts, becoming a management alternative against this stress. The experiment was carried in buckets in a greenhouse, a 3x4 factorial design was used with four replicates in a completely randomized design, being the first factor the saline stress, caused by irrigation with water enriched with sodium chloride $\left(\mathrm{NaCl}\right.$ ), in doses of 0 (control); 8 and $16 \mathrm{mM}$, and the second factor, the fertilization with $\mathrm{SiO}_{2}$, at doses of 0 (control); 1000; 2000 and $3000 \mathrm{~kg} \mathrm{ha}^{-1}$, using rice husk ash as $\mathrm{SiO}_{2}$ source. $\mathrm{SiO}_{2}$ doses of up to $2000 \mathrm{~kg}^{-1}$ had to an increase of the number of ears and seed weight per plant. The application of rice husk ash increased the weight of thousand seeds and did not affect the germination of the seeds obtained, neither the seedlings dry weight.

Keywords: physiological quality, rice husk, silicon, Triticum aestivum L. 


\section{INTRODUÇÃO}

O trigo é uma cultura anual, cultivada entre as estações de inverno e primavera e o seu grão é processado em farinha, a qual pode ser consumida na forma de pão, massa, bolos, biscoitos entre outros alimentos. Quando o padrão de qualidade não atinge as exigências para o consumo humano, é usado como ração animal (Embrapa trigo, 2013).

O grão de trigo representa cerca de $30 \%$ da produção mundial de cereais (Miranda, 2006) e no Brasil ocupou a quinta maior área semeada na safra 2012/2013, depois da soja, milho, feijão e arroz (Conab, 2013). Esta espécie é considerada como acumuladora de silício (Si) devido ao processo ativo de absorção deste nutriente pelas raízes, atingindo teores médios de Si nas folhas acima de $10 \mathrm{~g} \mathrm{~kg}^{-1} \mathrm{de}$ matéria seca (Oliveira, 2009). Além disso, o trigo é considerado medianamente tolerante ao sal, no entanto o seu desenvolvimento em meios salinos pode prejudicar o crescimento e a produtividade (Medeiros et al., 2010).

A produtividade agrícola no mundo é, em grande parte, limitada pelos efeitos da salinidade em torno de $50 \%$ das áreas regadas usadas na agricultura. Isso ocorre devido à falta de recursos hídricos de boa qualidade, do uso excessivo de fertilizantes nas lavouras, drenagem insuficiente do solo, além do uso de água salgada em algumas explorações agrícolas por parte de alguns agricultores (USDA, 2013). No Brasil, estima-se que cerca de 20 a $25 \%$ das áreas regadas, apresentam algum grau de salinidade, sendo que a maior parte dessas terras se encontra localizada na região do semiárido brasileiro.

De acordo com Dias e Blanco (2010), o efeito negativo que os sais causam às plantas pode ser devido a três fatores. O primeiro é a dificuldade na absorção de água, devido à presença de sais na solução do solo, aumentando o potencial osmótico do mesmo até atingir níveis em que as plantas não têm capacidade para superar esse potencial e absorver água. Dependendo do grau de salinidade, a planta pode até perder a água que se encontra no seu interior causando plasmólise, que é um fenómeno em que a água das células da planta passa para a solução do solo. O segundo fator é a toxicidade por iões específicos, o que acontece quando as plantas absorvem os sais do solo junto com a água, ocasionando toxicidade por excesso de sais absorvidos. A alta concentração de sais na planta promove danos no citoplasma das células, principalmente nas dos ápices das folhas, onde a planta vai perder, por transpiração, a água absorvida e como consequência aumentam os teores de sais no seu interior devido ao facto de que os mesmos não são transpirados juntamente com a água. Este tipo de dano reduz significativamente o rendimento das lavouras e o seu nível vai depender do tempo de stresse, da concentração de iões, da tolerância das cultivares à salinidade e do uso da água. O terceiro fator é a interferência indireta dos sais nos processos fisiológicos da planta. Isso acontece quando as altas concentrações de catiões, principalmente de sódio, interferem nas propriedades físico-químicas do solo, afetando a disponibilidade de outros elementos, e assim, indiretamente o normal desenvolvimento das plantas.

O uso de silício (Si) na agricultura possui vários benefícios para as plantas, como o aumento da produtividade, tolerância a ataques de pragas e doenças, diminuição dos efeitos de metais tóxicos e tolerância ao stresse salino e hídrico, entre outros (Rodrigues et al., 2011). Segundo Dias e Blanco (2010), o Si pode conferir certo grau de tolerância das plantas ao sal, da mesma forma que o $\mathrm{K}$ e o Ca, pois a absorção destes iões contribui para manter altas razões K/Na na planta. No entanto, ainda não foram descobertos nem completamente elucidados todos os mecanismos pelos quais o silício contribui para aumentar a tolerância ao stresse salino. Prova disto, é que alguns autores têm proposto diversas hipóteses tentando explicar o efeito do silício sobre o stresse salino, porém nenhuma constituiu uma evidência clara; dentro destas, três têm ganho maior aceitação na comunidade científica. A primeira é que o Si diminui a concentração de sais na planta devido à diminuição da transpiração por acumulação do elemento nas folhas, a segunda é que o silício diminui o transporte de Na nas raízes e a terceira é que o elemento tem funções fisiológicas que aumentam o metabolismo antioxidante (Shi et al., 2013).

Atualmente, existem vários subprodutos industriais que servem como fontes de silício e que podem ser usados na agricultura, nomeadamente a cinza de casca de arroz que é um subproduto da indústria arrozeira que se obtém quando a casca do arroz, extraída no beneficiamento, é carbonizada em fornalhas ou fornos especiais a temperaturas controladas. A cinza de casca de arroz pode chegar a conter em média $92 \%$ de sílica $\left(\mathrm{SiO}_{2}\right)$ (Foletto et al., 2005). 
Estudos estão sendo conduzidos visando identificar a forma de aplicação mais eficiente deste material.

Conforme pesquisas realizadas por Lima et al. (2011), a aplicação de silício na solução nutritiva na cultura de milho sob stresse salino, atenuou o efeito negativo causado pelo sal sobre o crescimento das plantas; porém, num mesmo ensaio realizado com feijão de corda, não foram encontrados resultados semelhantes. Igualmente, Tuna et al. (2008) observaram que o silício aplicado a plantas de trigo submetidas a stresse salino diminuiu a permeabilidade da membrana plasmática ao sódio, mantendo-a para o potássio e cálcio, aliviando o stresse causado pelo sal. Além disso, observaram que o transporte de sódio dentro das raízes das plantas foi moderadamente reduzido pela adição de silício em condições de stresse salino. Já Miranda et al. (2002) verificaram que o silício não propiciou efeitos benéficos sobre a produção de matéria seca de folhas, caule e raízes de moringa (Moringa oleifera) submetidas a stresse salino.

Embora se tenha pesquisado sobre alguns dos efeitos do Si nas plantas, poucos são os estudos que avaliam o efeito do silício usado em condições de salinidade sobre a produção e qualidade de sementes de trigo. Assim, este trabalho teve como objetivo avaliar o efeito da fertilização com cinza de casca de arroz, como fonte de silício, sobre a qualidade fisiológica de sementes de trigo produzidas sob stresse salino.

\section{MATERIAL E MÉTODOS}

O ensaio foi realizado em estufa-de-vegetação na Faculdade de Agronomia “Eliseu Maciel" (FAEM) e no Laboratório Didático de Análise de Sementes, do Programa de Pós-graduação em Ciência e Tecnologia de Sementes da Universidade Federal de Pelotas (UFPel). Sementes de trigo, cultivar Quartzo, foram semeadas em baldes de 10 litros contendo solo, colhido do horizonte A1 de um Panossolo Háplico Eutrófico solódico (Streck et al., 2008) pertencente à unidade de mapeamento Pelotas com as seguintes características: $\mathrm{pH}$ em água: 5,1; Ca: 2,1 $\mathrm{cmol}_{\mathrm{c}} \mathrm{dm}^{-3} ; \mathrm{Mg}:$ 0,8 $\mathrm{cmol}_{\mathrm{c}} \mathrm{dm}^{-3} ; \mathrm{Al}: 0,8 \mathrm{cmol}_{\mathrm{c}} \mathrm{dm}^{-}$ 3; H+Al: 3,9 $\mathrm{cmol}_{\mathrm{c}} \mathrm{dm}^{-3} ; \mathrm{CTC}_{\text {efetiva }}: 3,8 \mathrm{cmol}_{\mathrm{c}} \mathrm{dm}^{-3}$; Saturação por Al: $21 \%$; Saturação por bases: $44 \%$; $\mathrm{CTC}_{\mathrm{pH7.0}}: 6,9 \mathrm{cmol}_{\mathrm{c}} \mathrm{dm}^{-3}$; Materia Orgánica: 1,4\%; P (Mehlich): 1,8 $\mathrm{mg} \mathrm{dm}^{-3}$; K: $40 \mathrm{mg} \mathrm{dm}^{-3}$; Cu: 2,1 mg $\mathrm{dm}^{-3}$; Zn: 0,5 mg dm-3; B: 0,4 $\mathrm{mg} \mathrm{dm}^{-3}$; Fe: $1500 \mathrm{mg}$ dm-3 Mn: $115 \mathrm{mg} \mathrm{dm}^{-3}$ e Na: $16 \mathrm{mg} \mathrm{dm}^{-3}$. Em cada balde foram aplicados 13,5 g de calcário dolomítico 15 dias antes da sementeira, e adubado por incorporação, com $2 \mathrm{~g}$ de ureia, 3,5 g de superfosfato simples e 0,6 g de cloreto de potássio no momento da sementeira. No início do afilhamento foi aplicado mais um grama de ureia em cobertura. Estas práticas foram realizadas considerando o resultado e interpretação da análise de solo realizada pelo Laboratório de Análise de Solos da Faculdade de Agronomia Eliseu Maciel da UFPel e concordando com as indicações técnicas para a safra de trigo e triticale 2012 (Embrapa agropecuária oeste, 2011).

A fertilização com cinza de casca de arroz foi realizada também à sementeira. $\mathrm{O}$ ensaio foi realizado em esquema fatorial $3 \times 4$ com quatro repetições sob delineamento inteiramente casualizado, sendo o primeiro fator o stresse salino, causado pela rega realizada durante toda a cultura com cloreto de sódio $(\mathrm{NaCl})$, em doses de 0 (controlo), 8 e $16 \mathrm{mM}$ e o segundo fator, a fertilização com cinza de casca de arroz rica em silício em doses de 0 (controlo), 1000, 2000 e $3000 \mathrm{~kg} \mathrm{ha}^{-1}$ de sílica $\left(\mathrm{SiO}_{2}\right)$, o qual equivale à aplicação de 0 (controlo), 1087, 2174 e $3261 \mathrm{~kg} \mathrm{ha}^{-1}$ de cinza de casca de arroz, aplicando-se a cada balde 0 (controlo), 5,43; 10,86 e 16,29 g de cinza de casca de arroz, respectivamente. As quantidades de cinza de casca de arroz aplicadas foram calculadas considerando que a camada arável da cultura do trigo em um hectare é de dois milhões de litros, que o volume de solo usado em cada balde foi de 10 litros e que cinza de casca de arroz contem 92\% de $\mathrm{SiO}_{2}$ (Foletto et al., 2005).

Em cada balde foram semeadas 12 sementes, realizando-se um desbaste aos 15 dias após a emergência, deixando somente as cinco plantas de melhor aspecto em cada balde, considerando uma distribuição homogénea na superfície do balde para serem conduzidas até à colheita, a qual ocorreu quando mais de três quartos das espigas apresentaram cor dourada, indicando a maturidade fisiológica das sementes. As mesmas foram então colhidas, embaladas em sacos de papel e secas em estufa com circulação forçada de ar até atingirem $13 \%$ de humidade, momento em que ocorreu a debulha e o armazenamento em câmara fria. As variáveis resposta obtidas foram:

Número de espigas por planta: No momento da colheita, contou-se o total de espigas colhidas de cada planta. As mesmas foram embaladas em sacos de 
papel identificando-os com o número do tratamento e repetição.

Número de espigas com sementes por planta: Após a secagem das sementes, no laboratório foi determinado o número de espigas por planta que possuíam sementes.

Peso de espigas não debulhadas por planta: Foi retirado o colmo de todas as espigas e, posteriormente, pesou-se o conjunto de espigas em balança analítica e o resultado foi expresso em gramas.

Peso de sementes produzidas por planta: Após a debulha, as sementes foram limpas e pesadas em balança analítica, obtendo-se o peso em gramas das sementes colhidas de cada planta.

Peso de espigas debulhadas por planta: Obtido pela diferença entre o peso de espigas não debulhadas e o peso de sementes produzidas por planta.

Número de sementes por espiga: No momento da debulha foi contado o número total de sementes produzidas por planta. Esta quantidade foi dividida pelo número de espigas com sementes, obtendo-se assim o valor médio de sementes por espiga.

Peso de mil sementes: Contaram-se oito repetições de 100 sementes cada, calculando-se o peso de mil sementes conforme as Regras para Análise de Sementes (Brasil, 2009).

Teste de germinação: Realizado em rolos de papel para germinação (Germitest $\AA$ ) humedecidos com água destilada em proporção de 2,5 vezes o seu peso seco. Foram usadas 200 sementes por repetição distribuídas em quatro rolos de papel com 50 sementes cada. A temperatura de germinação foi de $20^{\circ} \mathrm{C}$ e a contagem feita aos quatro e oito dias após a sementeira conforme as Regras para Análise de Sementes RAS (Brasil, 2009). O resultado foi expresso em percentagem de plântulas normais.

Teste de primeira contagem de germinação: Realizado em conjunto com o teste de germinação, computando a percentagem de plântulas normais aos quatro dias após a sementeira, conforme as RAS (Brasil, 2009).

Comprimento de plântula: Conduzido conforme a metodologia descrita por Nakagawa (1999), usando-se 15 sementes para cada repetição e medindo com uma régua o comprimento da parte aérea e o comprimento da raiz de 10 plântulas normais, selecionadas aleatoriamente para cada repetição aos oito dias após a sementeira. Os resultados foram expressos em metros, através da média das 10 plântulas medidas.

Massa da Matéria seca de plântula: Realizado com as mesmas plântulas usadas no teste de comprimento de plântula. A parte aérea e raiz foram separadas e cada repetição colocada em sacos de papel e levada para secar em estufa com circulação forçada de ar, regulada à temperatura de $60 \pm 2{ }^{\circ} \mathrm{C}$, até atingir peso constante (Krzyzanowski et al., 1999). Posteriormente, as amostras foram pesadas em balança de precisão com 4 casas decimais, sendo os resultados expressos em g plântula-1.

Os resultados obtidos foram submetidos a análise de variância. Realizou-se uma comparação de médias pelo teste de Tukey para a o fator rega salina e regressão polinomial para a cinza de casca de arroz, ambos com $5 \%$ de probabilidade, utilizando o programa estatístico WinStat versão 1.0 (Machado e Conceição, 2003). Os dados em percentagem foram submetidos à transformação arc.sen $(\sqrt{ } x / 100)$.

\section{RESULTADOS E DISCUSSÃO}

A análise de variância demonstrou que os tratamentos aplicados não produziram efeito sobre o número de sementes por espiga (Quadro 1) nem sobre a massa da matéria seca da parte aérea e raiz das plântulas oriundas das sementes produzidas (Quadro 2). O número de espigas por planta, número de espigas com sementes por planta, peso de espigas não debulhadas por planta, peso de sementes produzidas por planta e peso de espigas debulhadas por planta apresentaram resposta somente à aplicação de cinza de casca de arroz, mas não à aplicação de sal por meio da água de rega nem à interação entre os fatores. Para o peso de mil sementes, comprimento da parte aérea e raiz das plântulas oriundas das sementes produzidas observou-se efeito da interação entre os fatores rega salina e cinza de casca de arroz. Já para a percentagem de germinação e primeira contagem de germinação das sementes produzidas, observou-se unicamente efeito do fator sal.

A variável produção de espigas ajustou-se a um modelo quadrático em função da dosagem de 
Quadro 1 - Peso de Mil Sementes (PMS) e Número de Sementes por Espiga (SE), de plantas de trigo, cv. Quartzo, cultivadas com aplicação de concentrações de $\mathrm{NaCl}$ na água de rega durante o desenvolvimento da cultura e da aplicação de doses de $\mathrm{SiO}_{2}$ em forma de cinza de casca de arroz, via incorporação no solo

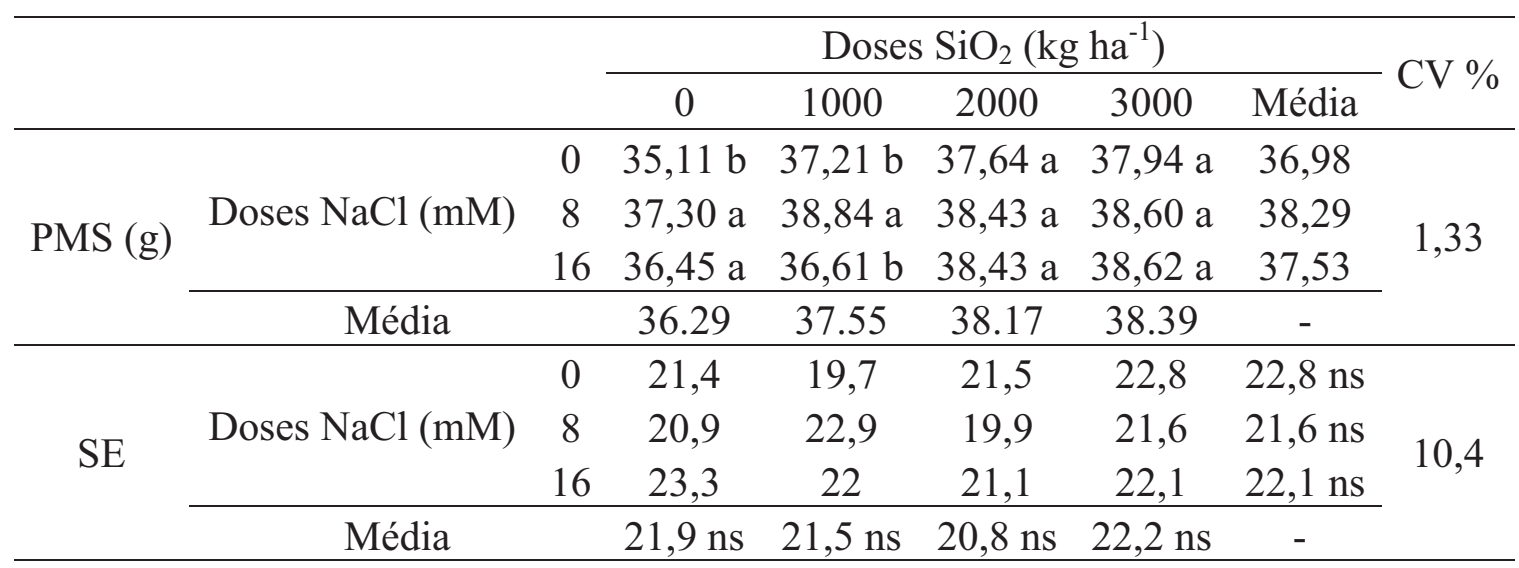

Quadro 2 - Porcentagem de Germinação (G), Primeira contagem de Germinação (PCG), Comprimento da Parte Aérea (CPA), Comprimento da Raiz (CA), Massa Seca da Parte Aérea (MSPA) e Massa Seca da Raiz (MSR), de plântulas oriundas de sementes produzidas por plantas de trigo, cv. Quartzo, cultivadas com aplicação de concentrações de $\mathrm{NaCl}$ na água de rega durante o desenvolvimento da cultura e da aplicação de doses de $\mathrm{SiO}_{2}$ em forma de cinza de casca de arroz, via incorporação no solo

\begin{tabular}{|c|c|c|c|c|c|c|c|c|}
\hline & & & \multicolumn{5}{|c|}{ Doses $\mathrm{SiO}_{2}\left(\mathrm{~kg} \mathrm{ha}^{-1}\right)$} & \multirow{2}{*}{$\begin{array}{c}\mathrm{CV} \\
\%\end{array}$} \\
\hline & & & 0 & 1000 & 2000 & 3000 & Média & \\
\hline \multirow{4}{*}{$\mathrm{G}(\%)$} & Doses & 0 & 98 & 98 & 98 & 98 & $98 \mathrm{~b}$ & \multirow{4}{*}{0,79} \\
\hline & $\mathrm{NaCl}$ & 8 & 99 & 99 & 100 & 99 & 99 a & \\
\hline & $(\mathrm{mM})$ & 16 & 98 & 99 & 98 & 99 & $98 \mathrm{~b}$ & \\
\hline & Média & & 98 & 99 & 99 & 99 & - & \\
\hline \multirow{4}{*}{ PCG (\%) } & Doses & 0 & 86 & 89 & 90 & 86 & $88 \mathrm{~b}$ & \multirow{4}{*}{2,66} \\
\hline & $\mathrm{NaCl}$ & 8 & 91 & 93 & 93 & 90 & $92 \mathrm{a}$ & \\
\hline & $(\mathrm{mM})$ & 16 & 92 & 89 & 92 & 91 & $91 \mathrm{a}$ & \\
\hline & Média & & 90 & 90 & 92 & 89 & - & \\
\hline \multirow{4}{*}{$\mathrm{CPA}(\mathrm{cm})$} & Doses & 0 & $13,1 \mathrm{a}$ & $13,6 \mathrm{a}$ & $13,1 \mathrm{a}$ & $14,4 \mathrm{a}$ & 13,5 & \multirow{4}{*}{6,00} \\
\hline & $\mathrm{NaCl}$ & 8 & $13,6 \mathrm{a}$ & $13,7 \mathrm{a}$ & $13,3 \mathrm{a}$ & $14,1 \mathrm{a}$ & 13,7 & \\
\hline & $(\mathrm{mM})$ & 16 & $12,7 \mathrm{a}$ & $14,3 \mathrm{a}$ & $13,3 \mathrm{a}$ & $12,4 \mathrm{~b}$ & 13,1 & \\
\hline & Média & & 13,1 & 13,9 & 13,2 & 13,6 & - & \\
\hline \multirow{4}{*}{$\mathrm{CR}(\mathrm{cm})$} & Doses & 0 & $15,1 \mathrm{a}$ & $15,7 \mathrm{a}$ & $15,4 \mathrm{ab}$ & $16,6 \mathrm{a}$ & 15,7 & \multirow{4}{*}{4,14} \\
\hline & $\mathrm{NaCl}$ & 8 & $15,2 \mathrm{a}$ & $16,3 \mathrm{a}$ & $14,5 \mathrm{~b}$ & $16,2 \mathrm{a}$ & 15,6 & \\
\hline & $(\mathrm{mM})$ & 16 & $14,1 \mathrm{a}$ & $16,6 \mathrm{a}$ & $16,2 \mathrm{a}$ & $14,4 \mathrm{~b}$ & 15,3 & \\
\hline & Média & & 14,8 & 16,2 & 15,4 & 15,8 & - & \\
\hline \multirow{4}{*}{$\begin{array}{c}\text { MSPA } \\
\quad(\mathrm{g})\end{array}$} & Doses & 0 & 0,0831 & 0,0904 & 0,0894 & 0,0895 & $0,0881 \mathrm{~ns}$ & \multirow{4}{*}{7,56} \\
\hline & $\mathrm{NaCl}$ & 8 & 0,0922 & 0,0852 & 0,0946 & 0,0916 & $0,0909 \mathrm{~ns}$ & \\
\hline & $(\mathrm{mM})$ & 16 & 0,0800 & 0,0911 & 0,0932 & 0,0867 & $0,0877 \mathrm{~ns}$ & \\
\hline & Média & & $0,0851 \mathrm{~ns}$ & $0,0889 \mathrm{~ns}$ & $0,0924 \mathrm{~ns}$ & $0,0893 \mathrm{~ns}$ & - & \\
\hline \multirow{4}{*}{$\operatorname{MSR}(\mathrm{g})$} & Doses & 0 & 0,0715 & 0,0740 & 0,0721 & 0,0747 & $0,0731 \mathrm{~ns}$ & \multirow{4}{*}{8,89} \\
\hline & $\mathrm{NaCl}$ & 8 & 0,0731 & 0,0688 & 0,0712 & 0,0727 & $0,0714 \mathrm{~ns}$ & \\
\hline & $(\mathrm{mM})$ & 16 & 0,0634 & 0,0700 & 0,0696 & 0,0787 & $0,0704 \mathrm{~ns}$ & \\
\hline & Média & & $0,0693 \mathrm{~ns}$ & $0,0709 \mathrm{~ns}$ & $0,0710 \mathrm{~ns}$ & $0,0754 \mathrm{~ns}$ & - & \\
\hline
\end{tabular}


cinza de casca de arroz, crescendo com o aumento da dose e atingindo o ponto de máxima eficiência com o uso de $2120 \mathrm{~kg} \mathrm{ha}^{-1}$ de $\mathrm{SiO}_{2}$; quando se utilizaram doses maiores a produção de espigas começou a diminuir (Figura 1a). Comportamento idêntico foi observado no número de espigas que produziram sementes, atingindo a máxima produção de espigas nos 2093 kg ha-1 de $\mathrm{SiO}_{2}$ (Figura 1b). O peso de espigas não debulhadas (Figura 1c), ajustou-se a um modelo linear em função da fertilização com cinza de casca de arroz, aumentando a uma taxa de 0,4 $\mathrm{g} \mathrm{Mg}^{-1}$ de $\mathrm{SiO}_{2}$ aplicado, enquanto o peso das sementes produzidas, se ajustou a um modelo quadrático negativo em função das doses de cinza de casca de arroz aplicadas, crescendo conforme aumentou a dosagem de cinza de casca de arroz até à dose de $2400 \mathrm{~kg} \mathrm{ha}^{-1}$ de $\mathrm{SiO}_{2}$ onde se manteve estável (Figura 1d). Finalmente, o peso das espigas debulhadas apresentou um comportamento linear, aumentando a uma taxa de $0,1 \mathrm{~g} \mathrm{Mg}^{-1}$ de $\mathrm{SiO}_{2}$ aplicado (Figura 1e).

Considerando os resultados obtidos, observa-se que a produção de espigas aumenta gradualmente com o aumento da dosagem de cinza de casca de

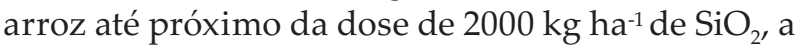
partir da qual se observa que o número de espigas por planta e número de espigas com sementes por planta não sofreram alterações. Igualmente se observou que o peso das espigas debulhadas e o peso
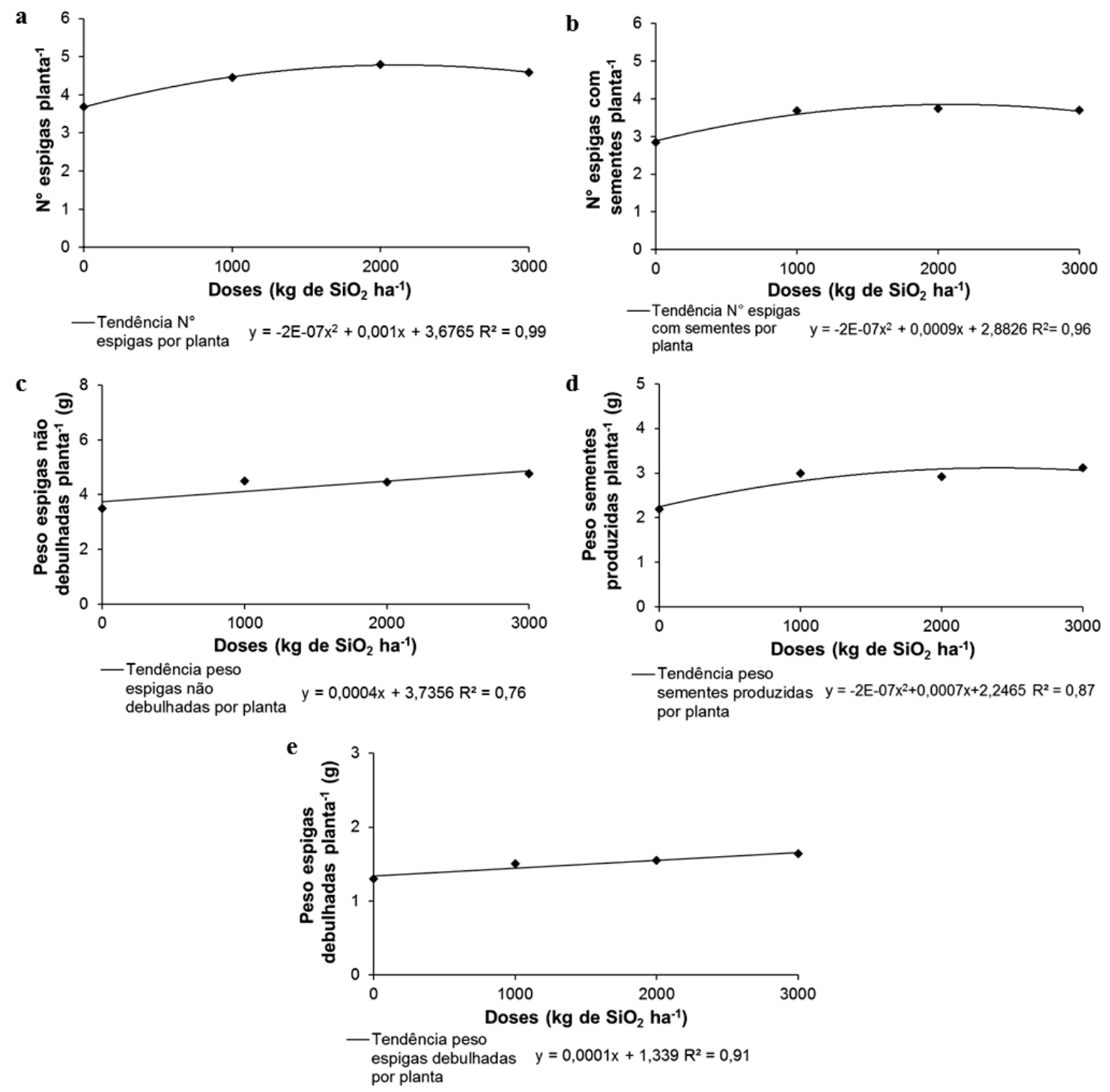

Figura 1 - Número de espigas por planta (a), CV\%=15,73. Número de espigas com sementes por planta (b), CV\%=18,36; Peso de espigas não debulhadas por planta (c), CV\%=14,76; Peso de sementes produzidas por planta, $C V \%=14,76$; Peso de espigas debulhadas por planta (d), CV\%=16,44. Figuras (média das três concentrações de sal) em função da fertilização com $\mathrm{SiO}_{2}$ em forma de cinza de casca de arroz por incorporação no solo na cultura de trigo, cv. Quartzo. 
das espigas não debulhadas sofreram incrementos com o aumento da dosagem de cinza de casca de arroz, porém o peso das sementes produzidas por planta manteve-se estável a partir da dose de 2000 $\mathrm{kg} \mathrm{ha}{ }^{-1} \mathrm{de}_{\mathrm{SiO}_{2}}$. Os resultados obtidos neste ensaio não estão de acordo com os encontrados por Segalin et al. (2013), que não observaram diferenças na produção de sementes de trigo quando fertilizado via foliar com várias doses de silício. No entanto, Pershin et al. (1995) observaram que a fertilização com silício na cultura do arroz aumenta o rendimento e o peso de mil sementes. Igualmente Singh et al. (2005) observaram que a fertilização com silício em plantas de arroz aumentou a produção de matéria seca da planta, a altura da planta e a produtividade de grãos. Já num outro ensaio com trigo, Tahir et al. (2006), observaram que a aplicação de silicato de cálcio às plantas foi positiva para o rendimento de sementes e matéria seca da planta, tanto em condições normais quanto em condições de stresse salino. Avaliando a fertilização silicatada via solo em condições adequadas de cultivo, Tavares et al. (2014), observaram incremento no número de sementes, peso hectolítrico e rendimento de sementes de trigo.

O peso de mil sementes (PMS) apresentou interação significativa entre os fatores sal e aplicação de cinza de casca de arroz (Quadro 1 e Figura 2). Esta variável não foi influenciada pela quantidade de sal quando estas foram combinadas com as doses

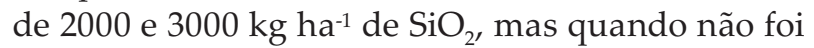
aplicada cinza de casca de arroz, o peso de mil sementes foi maior quando as plantas foram regadas com água salina. Na Figura 2 pode observar-se que quando a rega foi feita com água sem sal e com água de concentração de $8 \mathrm{mM}$ de sal, o peso de mil sementes se ajustou a um modelo quadrático negativo e quando a rega foi efetuada com água de concentração de $16 \mathrm{mM}$ de $\mathrm{NaCl}$, esta variável teve comportamento linear positivo. De uma forma geral observou-se que o PMS foi maior quando a rega foi feita com água sem sal do que com água salina, além do aumento da dosagem de $\mathrm{SiO}_{2}$ ter sido positivo para o peso de mil sementes independentemente da qualidade da água de rega.

Toledo et al. (2012), não encontraram diferenças significativas no peso de mil sementes em várias cultivares de aveia branca e trigo produzidas com fertilização foliar de silício. Igualmente, Fonseca (2012), não detetou efeito do tratamento de sementes de trigo com silício sobre o peso de mil sementes. No

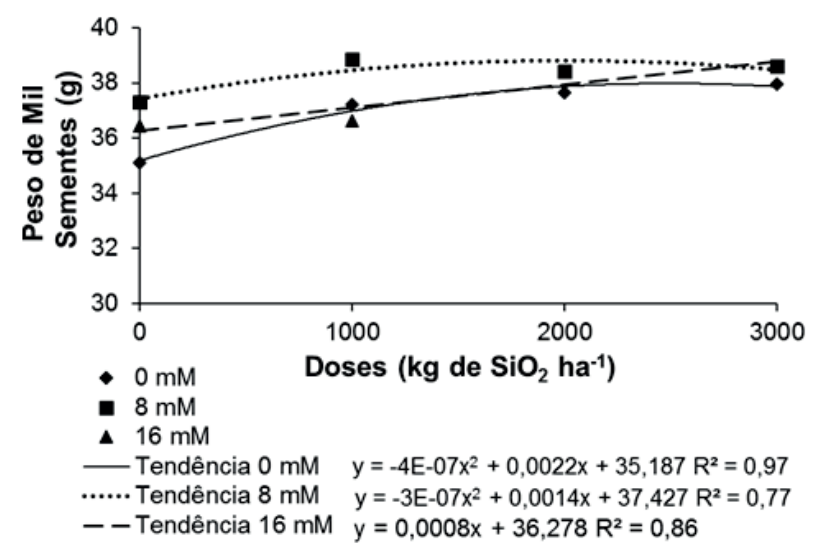

Figura 2 - Peso de mil sementes (PMS) em função da interação entre a rega com água salina e a fertilização com $\mathrm{SiO}_{2}$ em forma de cinza de casca de arroz por incorporação no solo na cultura de trigo, cv. Quartzo. mM: milimolar.

entanto, Oliveira (2013) observou efeito positivo do tratamento com silício em sementes de soja sobre o peso de mil sementes.

No quadro 2 é possível observar que a percentagem de germinação foi maior na rega com água de concentração de $8 \mathrm{mM}$, enquanto a primeira contagem de germinação teve melhor desempenho quando as plantas foram regadas com ambas as concentrações de $\mathrm{NaCl}$, em relação ao controlo (sem sal). Este resultado discorda do encontrado por Matichenkov et al. (2005) que observaram que o silício aumentou a percentagem de germinação de sementes de trigo em condições de stresse salino. Lemes (2013) também observou que sementes de arroz produzidas em condições de stresse salino apresentaram menor número de plântulas normais, tanto no teste de germinação como na primeira contagem de germinação, comparadas às sementes produzidas sem stresse.

Analisando os dados referentes ao comprimento da parte aérea das plântulas (Figura 3), pode-se observar que, quando as plantas foram regadas com água sem sal e com água de concentração de $8 \mathrm{mM}$ de $\mathrm{NaCl}$, a dosagem de cinza de casca de arroz não teve efeito significativo. Quando as plantas foram regadas com água de concentração de $16 \mathrm{mM}$, os resultados ajustaram-se a um modelo quadrático, aumentando o comprimento da parte aérea à medida que se aumentaram as doses de cinza de casca de arroz, até atingir o topo máximo na dose de $1000 \mathrm{~kg} \mathrm{ha}^{-1}$ de $\mathrm{SiO}_{2}$ quando o comprimento da parte aérea da plântula começou a diminuir. 

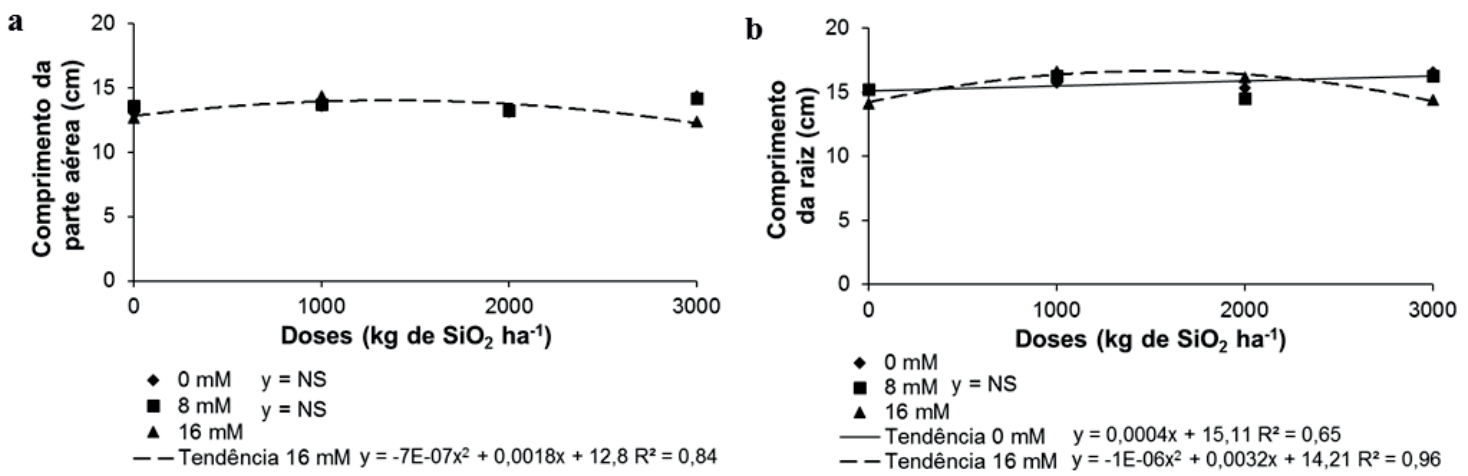

Figura 3 - Comprimento da parte aérea das plântulas oriundas das sementes produzidas (a). Comprimento da raiz das plântulas oriundas das sementes produzidas (b). Figuras em função da interação entre a rega com água salina e a fertilização com $\mathrm{SiO}_{2}$ em forma de cinza de casca de arroz por incorporação no solo na cultura de trigo, cv. Quartzo. mM: milimolar. NS= não significativo.

Conforme o Quadro 2 pode-se observar que a dosagem de sal não teve efeito sobre o comprimento da parte aérea das plântulas quando se aplicou $\mathrm{SiO}_{2}$ nas doses de 0; 1000 e $2000 \mathrm{~kg} \mathrm{ha}^{-1}$, no entanto, quando se adubaram as plantas com $3000 \mathrm{~kg} \mathrm{ha}^{-1}$ de sílica, o comprimento da parte aérea foi significativamente menor quando a rega foi feita com água com uma concentração de $16 \mathrm{mM}$ de $\mathrm{NaCl}$.

O comprimento da raiz das plântulas apresentou resposta à rega com água salina quando as plantas foram adubadas com as doses de 2000 e 3000 kg ha-1 de $\mathrm{SiO}_{2}$ (Quadro 2), sendo o comprimento maior na rega com água com concentração de 16 $\mathrm{mM}$ e menor com a rega na dose de $8 \mathrm{mM}$ de $\mathrm{NaCl}$

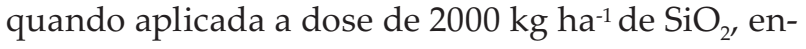
quanto, quando aplicada a dose de $3000 \mathrm{~kg} \mathrm{ha}^{-1} \mathrm{de}$ $\mathrm{SiO}_{2}$, a rega com água com concentração de $16 \mathrm{mM}$ de $\mathrm{NaCl}$ afetou o comprimento da raiz. Quando se

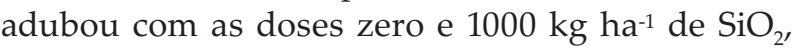
o comprimento da raiz não apresentou resposta à dosagem de sal aplicada na rega. Também se pode observar, que as doses de cinza de casca de arroz não têm efeito sobre o comprimento da raiz quando as plantas são regadas com água com concentração de $8 \mathrm{mM}$ de $\mathrm{NaCl}$, no entanto quando as plantas são regadas com água sem sal, observa-se uma resposta positiva à cinza de casca de arroz, aumentando de forma linear conforme aumenta a dosagem de $\mathrm{SiO}_{2}$ com uma taxa de $0,4 \mathrm{~g} \mathrm{Mg}^{-1}$ de sílica aplicada. Igualmente se observou que quando as plantas foram regadas com água com uma concentração de $16 \mathrm{mM}$ de $\mathrm{NaCl}$, o comprimento de raiz apresentou um comportamento do tipo quadrático, aumentando até atingir o topo na dose de

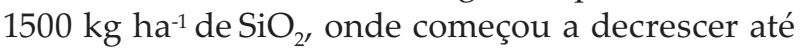
igualar a dose zero (Figura 3). Fonseca (2012), não encontrou diferenças significativas no comprimento da parte aérea de plântulas de trigo oriundas de sementes produzidas a partir de sementes cobertas com silicato de alumínio em várias doses. Em ensaio similar, mas com soja, Rufino (2010) observou que o silício tem uma influência positiva sobre o comprimento da parte aérea das plântulas oriundas das sementes produzidas.

\section{CONCLUSÕES}

A cinza de casca de arroz como fonte de silício, até

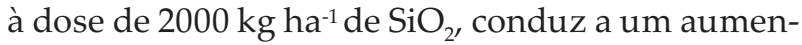
to do número de espigas e do peso de sementes por planta.

A aplicação de sílica via solo, usando como fonte a cinza de casca de arroz, independente da presença de stresse salino, aumenta o peso de mil sementes.

A cinza de casca de arroz não afeta a germinação das sementes produzidas nem a massa da matéria seca das plântulas oriundas das ditas sementes.

\section{REFERÊNCIAS BIBLIOGRÁFICAS}

Brasil (2009) - Regras para análise de sementes. Brasília, Ministério da Agricultura, Pecuária e Abastecimento/ACS. 399 p.

Conab. (2013) - Acompanhamento de safra brasileira: grãos, décimo levantamento. Companhia Nacional de Abastecimento [cit. 2013-07-25].

http://www.conab.gov.br

Dias, N.S. e Blanco, F.F. (2010) - Efeito dos sais no solo e na planta. In: Gheyi, H.R; Dias, N.S. e Lacerda, C.F. 
(Eds). Manejo da salinidade na agricultura: estudos básicos e aplicados. Fortaleza, INCT Sal, 472 p.

Embrapa Agropecuaria Oeste (2012) - Informações Técnicas para Trigo e Triticale - safra 2012. Reunião da Comissão Brasileira de Pesquisa de Trigo e Triticale. Dourados, MS, 25 a 28 de julho de 2011.

Embrapa Trigo (2013) - Cultura do Trigo, Passo Fundo - RS. [cit. 2014-02-14].

http://www.cnpt.embrapa.br/culturas/trigo/ index.html.

Foletto, E.L.; Hoffmann, R.; Hoffmann, R.S.; Portugal Jr., U.L. e Jahn, S.L. (2005) - Aplicabilidade das cinzas da casca de arroz. Química Nova, vol. 28, n. 6 , p. $1055-1060$.

http://dx.doi.org/10.1590/S0100-40422005000600021

Fonseca, D.A.R. (2012) - Desempenho de sementes de trigo recobertas com silicato de alumínio. Dissertação de mestrado. Universidade Federal de Pelotas, Brasil. 59 p.

Krzyzanowski, C.F.; Vieira, R.D. e França Neto, J.B. (1999) -Vigor de sementes: conceitos e testes. Londrina, ABRATES. 218 p.

Lemes, E.S. (2013) - Aplicação de cinza da casca de arroz, via solo, como fonte de silício em arroz irrigado sob estresse salino. Dissertação de mestrado. Universidade Federal de Pelotas, Brasil. 68 p.

Lima, M.A.; Castro, V.F.; Vidal, J.B. e Filho, J.E. (2011) - Aplicação de silício em milho e feijão-de-corda sob estresse salino. Revista Ciência Agronômica, vol. 42, n. 2, p. 398-403.

Machado, A.A. e Conceição, A.R. (2003) - Sistema de análise estatística para Windows. WinStat. Versão 1.0. Pelotas. UFPel.

Matichenkov, V.V.; Kosobrukhov, A.A.; Shabnova, N.I. e Bocharnikova, E.A. (2005) - Plant response to silicon fertilizers under salt stress. Agrokhimiya, vol.10, p. 59-63.

Medeiros, J.F.; Nascimento, L.B. e Gheyi, H.R. (2010) - Manejo do solo-água-planta em áreas afetadas por sais. In: Gheyi, H.R; Dias, N.S. e Lacerda, C.F. (Eds) - Manejo da salinidade na agricultura: estudos básicos e aplicados. Fortaleza, INCT Sal, $472 \mathrm{p}$.

Miranda, J.R.P.; Carvalho, J.G.; Santos, D.R.; Freire, A.L.O.; Bertoni, J.C.; Melo J.R.M. e Caldas, A.L. (2002) - Silício e cloreto de sódio na nutrição mineral e produção de matéria seca de plantas de moringa (Moringa oleifera Lam.). Revista Brasileira da Ciência do Solo, vol. 26, n. 4, p. 957-965.

http://dx.doi.org/10.1590/S0100-06832002000400013

Miranda, M.Z. (2006) - Trigo: germinação e posterior extrusão para obtenção de farinha integral extrusada de trigo germinado. Embrapa Trigo, Passo Fundo. Documentos Online [cit. 2014-05-10]. <http:// www.cnpt.embrapa.br/biblio/do/p_do74.pdf>.

Nakagawa, J. (1999) - Testes de vigor baseados no desempenho das plântulas. In: Krzyzanowski, F.C.; Vieira, R. D. e França Neto, J.B. (Eds.) - Vigor de sementes: conceitos e testes. Londrina, ABRATES.

Oliveira, L.A. (2009) - Silício em plantas de feijão e arroz: absorção, transporte, redistribuição e tolerância ao cádmio. Tese de Doutoramento. Universidade de São Paulo, Brasil. 157 p.

Oliveira, S. (2013) - Silício oriundo da cinza de casca de arroz carbonizada como promotor do rendimento e da qualidade fisiológica de sementes de soja. Dissertação de mestrado. Universidade Federal de Pelotas, Brasil. 67 p.

Pershin, B.M.; Pershima, A.N. e Egorina, L.M. (1995) - Silicon and rice production in the Primorskii region. Agrikhimiya, vol. 10, p. 68-74.

Rodrigues, F.A.; Oliveira, L.A.; Korndörfer, A.P. e Korndörfer, G.H. (2011) - Silício: um elemento benéfico e importante para as plantas. Informações Agronômicas $\mathrm{N}^{\circ}$ 134. International Plant Nutrition Institute, Brasil.

Rufino, C.A. (2010) - Aplicação de cálcio, magnésio e silício nas sementes de soja. Dissertação de Mestrado. Universidade Federal de Pelotas, Brasil. 55 p.

Segalin, S.R.; Huth, C.; Rosa, T.A.; Pahins, D.B.; Mertz, L.M.; Nunes, U.R. e Martin, T.N. (2013) - Foliar application of silicon and the effect on wheat seed yield and quality. Journal of Seed Science, vol. 35, n. 1, p. 86-91. http://dx.doi.org/10.1590/S2317-15372013000100012

Shi, Y.; Wang, Y.; Flowers, T.J. e Gong, H. (2013) - Silicon decreases chloride transport in rice (Oryza sativa L.) in saline conditions. Journal of Plant Physiology. vol. 170, n. 9, p. 847-853. http:// dx.doi.org/10.1016/j.jplph.2013.01.018

Singh, A.K.; Singh, R. e Singh, K. (2005) - Growth, yield and economics of rice (Oryza sativa L.) as influenced by level and time of silicon application. Indian Journal of Agronomy, vol. 50, n. 3, p. 190-193.

Streck, E.V.; Kämpf, N.; Dalmolin, R.S.D.; Klamt, E., Nascimento, P.C.; Schneider, P.; Giasson, E. e Pinto, L.F.S. (2008) - Solos do Rio Grande do Sul. 2.ed. Porto Alegre, EMATER/RSASCAR, p. 222.

Tahir, M.A.; Rahmatullah; Aziz, T.; Ashraf, M.; Kanwal, S. e Maqsoos, M.A. (2006) - Beneficial effects of silicon in wheat (Triticum aestivum L.) under salinity stress. Pakistan Journal of Botany, vol. 5, n. 38, p. 1715-1722.

Tavares, L.C.; Fonseca, D.A.R; Rufino, C.A.; Oliveira, S. de; Brunes, A.P.; Villela, F.A. (2014) - Adubação silicatada em trigo: rendimento e qualidade de sementes. Revista de la Facultad de Agronomía, vol. 113 , n. 1, p. 94-99. 
Toledo, M.Z.; Castro, G.S.A.; Crusciol, C.A.C.; Soratto, R.P.; Cavariani, C.; Ishizuka, M.S. e Picoli, L.B. (2012) - Aplicação foliar de silício e qualidade fisiológica de sementes de aveiabranca e trigo. Semina: Ciências Agrárias, vol. 33, n. 5, p. 1693-1702.

h t tp://dx.doi.org/10.5433/16790359.2012v33n5p1693

Tuna, A.L.; Kayab, C.; Higgs, D.; Amador, B.M.; Aydemir, S. e Girgin, A.R. (2008) - Silicon improves salinity tolerance in wheat plants. Environmental and Experimental Botany, vol. 62, n. 1, p. 10-16. http://dx.doi.org/10.1016/j.envexpbot.2007.06.006 USDA (2013) - United States Department of Agriculture Frequently Asked Questions About Salinity. [cit. 2014-05-10].

http://www.ars.usda.gov/Aboutus/docs. htm?docid=10201. 